\title{
Evaluation of Human Discomfort from Combined Noise and Whole-Body Vibration in Passenger Vehicle
}

\author{
M. F. Aladdin ${ }^{1,2}$, N. A. A. Jaliil ${ }^{1 *}$, N. Y. Guan ${ }^{1}$, K. A. M. Rezali ${ }^{1}$ and S. A. Adam ${ }^{1}$ \\ ${ }^{1}$ Sound and Vibration Research Group, \\ Faculty of Mechanical and Manufacturing Engineering, Universiti Putra Malaysia, \\ 43400 Serdang, Selangor, Malaysia \\ Phone: +60389466336; Fax: +60386567122 \\ ${ }^{2}$ School of Engineering, Faculty of Innovation and Technology, \\ Taylor's University Malaysia, 47500, Subang Jaya, Selangor, Malaysia \\ *Email: MohdFarid.Aladdin@ taylors.edu.my
}

\begin{abstract}
Exposure to noise and whole-body vibration (WBV) has been a key element in determining comfort levels in transportation systems. In the automotive industry, researchers and engineers continuously work on reducing noise and vibration levels to minimize discomfort. Noise annoyance in vehicles results from structure-borne as well as air-borne noise from vehicle powertrain, tires and aeroacoustics. Whole-body vibration affects vehicle passenger comfort at the seat pan, back rest and feet. The objective of this research is to evaluate the comfort level of seated passengers in a vehicle from noise and whole-body vibration by considering both separate and combined modality. The noise and vibration data were recorded and analysed in two vehicles on the same highway road with four different speeds. The vibration exposure in vehicle were evaluated based on ISO2631-1:1997. Noise exposure was based on A-weighted sound pressure level. The combined discomfort on noise and vibration were quantified. The vibration results identified clear dominant of $\mathrm{z}$-axis vertical vibration on seat pan, backrest and feet in both vehicles. The discomfort of combined noise and vibration showed that vehicle B caused a higher discomfort level at the high vehicle speed of $90 \mathrm{~km} / \mathrm{h}$ and $110 \mathrm{~km} / \mathrm{h}$. The Relative Discomfort Indicator (RDI) were introduced to compare levels of discomfort from noise and vibration in different vehicles with varying speeds. The result suggests that the RDI value for vehicle A relative to vehicle $B$ is negative at higher vehicle speed which further indicates that at higher speed, vehicle $B$ have a higher discomfort level compared to vehicle A. The RDI value is expected to be useful for automotive Noise, vibration and harshness $(\mathrm{NVH})$ improvement.
\end{abstract}

Keywords: Combined noise and whole-body vibration; vehicle interior noise; wholebody vibration (WBV), relative discomfort indicator (RDI)

\section{INTRODUCTION}

Exposure to noise and Whole-Body Vibration (WBV) has been a key element in determining comfort levels in transportation systems. In the automotive industry, researchers and engineers continuously work on reducing noise and vibration levels to minimize discomfort. Noise annoyance in vehicles results from structure-borne as well as air-borne noise from vehicle engine, powertrain, tires and aeroacoustics. Whole-body vibration affects vehicle passenger comfort at the seat pan, back rest and feet. For a seated 
person, the comfort level is affected by a kyphotic spinal curvature which increases disk pressure, stretch posterior ligaments and hampered supply of nutrient to the nerves and lead to lower back pain (LBP) and discomfort[1]. The effect of LBP due to whole-body vibration is not instantly obvious and takes time before it starts to affect human health. A research related to an evaluation of whole-body vibration and back pain problem among light rapid transit (LRT) drivers[2] suggests a relation between back pain and daily vibration exposure.

In terms of discomfort, vibration in vehicles need to be evaluated as well. The discomfort due to vibration needs to be measured at the interfaces between the body and the vibrating environment at the seat surface, the back rest, the feet and the hand [3]. Currently the evaluation of discomfort from WBV is based on the measured data and verified with International Standard of ISO-2631-1:1997 - Mechanical vibration and shock : Evaluation of human exposure to whole-body vibration [4] or using British standard of BS6841:1987 - Guide to measurement and evaluation of human exposure to whole-body mechanical vibration and repeated shock [5]. Any interaction with other factors is neglected to avoid complexity. A study on whole-body vibration exposures in bus drivers by comparing a high floor coach and a low-floor city bus which are commonly used in long urban commuter routes suggested that WBV in high a coach bus is significantly higher on the road containing several speed humps, whereby on city streets and the freeway, the WBV exposure is just slightly different [6]. Another related study measured, evaluated and assessed WBV on 100 different vehicles according to BS6841:1987 and ISO 2631-1:1997 and figured out that assessments made using ISO 2631-1:1997 tend to underestimate risks from exposure to whole-body vibration compared to using BS6841:1987 [7].

The main reason is the difference in the frequency weighting in these two standards. Altinsoy [8] studied the quality attributes of automotive idle sounds and wholebody vibrations. The results suggest that the sound level alone is insufficient to describe the complexity of idle sound and vibration perception. Psychoacoustic metric of loudness, sharpness, roughness and fluctuation strength was proposed to be the basis for the development of perception index. Emotional aspect was found to be vital for the assessment of sound and vibration. In an evaluation of a two wheeler drive, Kumar [9] studied vibration dose value (VDV) and discomfort due to whole-body vibration exposure of a two wheeler driver and identified the pillion passenger feels more discomfort at higher speeds, and at speed breaker's height compared to the driver. Therefore, the passenger feels a more severe vibration compared to the driver. Purcell [10] conducted measurement and analysis of Human-body vibration exposure of heavy mobile equipment at an opencast mine in South Africa and identified impulsive whole-body vibration on all measured vehicles with $90.6 \%$ showed possibly dangerous levels of vibration exposure. Nahvi et al. [11] evaluated WBV in a passenger car at different speeds of 20, 40, 60 and $80 \mathrm{~km} / \mathrm{h}$ and identified that vibration energy concentration is at frequencies lower than 30 $\mathrm{Hz}$ and the vibration dose value increases proportionately to vehicle speed. Duerte and Melo [12] studied the influence of pavement type and speed on WBV in passenger vehicles by considering 3 types of vehicles and 5 vehicle speeds of 20, 30, 40, 50 and 60 $\mathrm{km} / \mathrm{h}$. The findings suggested that vibration exposure increased as speed increased, and that stone paved roads provide higher vibration exposure compared to asphalt roads. The vibration spectra also found to be intense at frequency below $30 \mathrm{~Hz}$.

In terms of sound quality in the vehicle cabin, the current evaluation is based on sound level and psychoacoustic parameters such as loudness, sharpness, roughness and fluctuation strength. Researchers used different ways to study interior vehicle noise. An 
experiment for evaluation of vehicle cabin noise using subjective and objective psychoacoustic analysis technique was conducted by using vibration data at the suspension system structure to evaluate the transfer path of the excitation energy into the vehicle cabin, which was compared with in-cabin psychoacoustics result. The findings suggest high correlation between both approaches [13]. Preliminary study of psychoacoustic bias in vehicle interior noise was conducted and the result suggest the correlation of bias in subjective evaluation among vehicle drivers from different vehicle categories [14]. In sound perception, Kaplanis [15] studied the perceptual aspects of reproduced sound in car cabin acoustics, and identified the importance of several acoustical properties of a car's interior on the perceived sound qualities. Al-Dhahebi [16] used a computational approach called Genetic Algorithm (GA) for optimizing a vehicle's interior noise and vibration, and was able to identify that the comfort level was influenced by the types of road surface, powertrain and vehicle design. Li and Huang [17] studied micro commercial vehicle interior noise based on sound quality analyses and identified that the loudness and sharpness were the influential factors of discomfort in the vehicle.

In the case of considering noise and vibration as combined modalities, Huang and Griffin investigated human discomfort produced by noise and whole-body vibration separately and in combination for the level of noise $70-88 \mathrm{dBA}$ SEL and vibration magnitude of $0.146-2.318 \mathrm{~ms}^{-1.75} \mathrm{VDV}$ [18]. The findings suggested that vibration did not significantly influence judgement of noise discomfort, but noise reduced vibration discomfort with increasing level of noise. Huang proposed the root-sum-square and linear regression model to predict comfort level from combined noise and vibration. In other research, Daruis studied a driver's perception on the influence of interior sound to vertical whole-body vibration in his vehicle and discovered that the annoyance on vibration was more affected by the presence of sound than the annoyance of sound with vibration presence [19]. A study on the contribution of noise and vertical vibration to the comfort in a driving car using a vehicle simulator was conducted, and the results suggested that the interaction of both stimuli was very small but the relative contributions of sound and vibration to comfort were different from the referenced existing model [20]. Maigrot, et al. [21] conducted two laboratory methods of assessing annoyance due to railway noise and vibration by considering total annoyance due to combined noise and vibration and partial annoyances due to each source in the presence of the other. The findings suggest that no difference was found between partial and total annoyance responses. Huang and Li [22] studied subjective discomfort from micro commercial vehicle vibration over different road conditions by recording noise and vibration from vehicle and reproduced the stimuli in lab environment. The findings suggested that vibration containing more high-frequency components caused greater discomfort than those with less highfrequency components.

In works of literature, three main research questions were identified; i) What is the difference in term of discomfort when evaluating vibration and noise separately and as combined modalities? ii) Is there any significant difference of discomfort when vehicles operate at different speeds? iii) How does the root-sum-square model predict discomfort from noise and vibration? The objective of the research is to evaluate the discomfort in passenger vehicle noise and vibration in combined and separately under different operating conditions. It was hypothesised that the combined effect of noise and vibration vary in different vehicles with different operating speeds. The trend in current related researches is to combine human response to different modalities such as noise and vibration. Human responses to vibration was studied by many scholars with available handbook for references [23] 


\section{METHODOLOGY}

\section{Noise and vibration data field Measurement}

Data of noise and vibration were recorded from two used vehicle named vehicle $A$ and vehicle B. Vehicle A is a Perodua Alza Advance 1.5L with the manufacturing year of 2013. Vehicle B is Perodua Myvi 1.5L with the manufacturing year of 2009. A Dytran SIT-PAD triaxial accelerometer with the sensitivity of $\mathrm{x}$-axis $93.3 \mathrm{mV} / \mathrm{g}$, the $\mathrm{y}$-axis of $99.5 \mathrm{mV} / \mathrm{g}$ and $\mathrm{z}$-axis of $100.3 \mathrm{mV} / \mathrm{g}$ was placed on the seat pan, backrest and feet to measure whole-body vibration on the seat-person interface as in Figure 1. A Pre-polarized free-field $1 / 2$ " microphone B\&K type 4189 with a sensitivity of $53.2 \mathrm{mV} / \mathrm{Pa}$ was placed at the ear level of a front passenger of the vehicle. The 4-channel portable ADASH vibration analyser was used to collect vibration and noise data. The data was then retrieved and analysed with MATLAB.

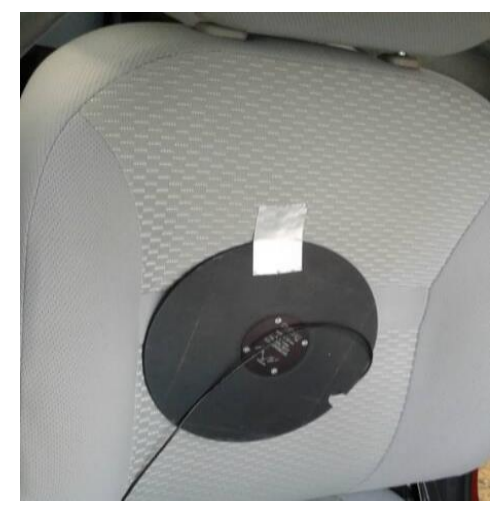

(a)

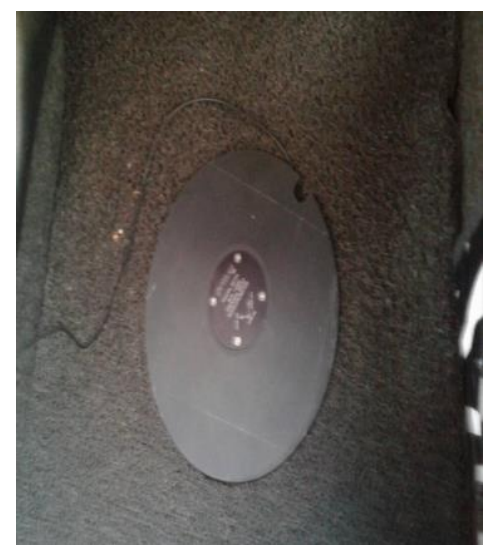

(c)

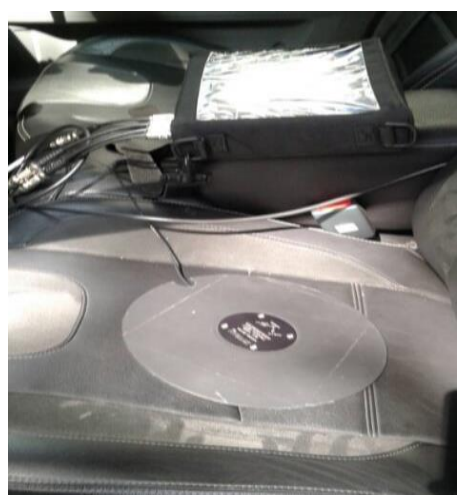

(b)

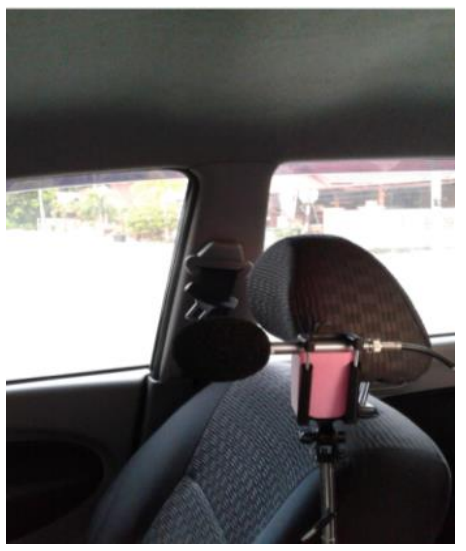

(d)

Figure 1. SIT-PAD accelerometer was placed on the (a) back seat, (b) seat pan and; (c) footrest of the front passenger side of the vehicle. The microphone was mounted at the ear level of the vehicle driver as in (d).

The positioning of the SIT PAD is according to the distance suggested in ISO10326-1:1992 - Mechanical vibration: Laboratory method for evaluating vehicle seat vibration Part 1: Basic requirement. The SITPAD was place on vehicle seat and backrest as in Figure 2. The measurements were not taken concurrently, but through the same identified highway road of New Klang Valley Expressway (NKVE) with four different 
speeds of $40 \mathrm{~km} / \mathrm{h}, 60 \mathrm{~km} / \mathrm{h}, 90 \mathrm{~km} / \mathrm{h}$ and $110 \mathrm{~km} / \mathrm{h}$. The speed limit of the highway road is $110 \mathrm{~km} / \mathrm{h}$. The noise measurement was taken three times for 60 seconds of each speed and then averaged out for analysis. The vibration data were taken only once for 60 seconds of every speed.

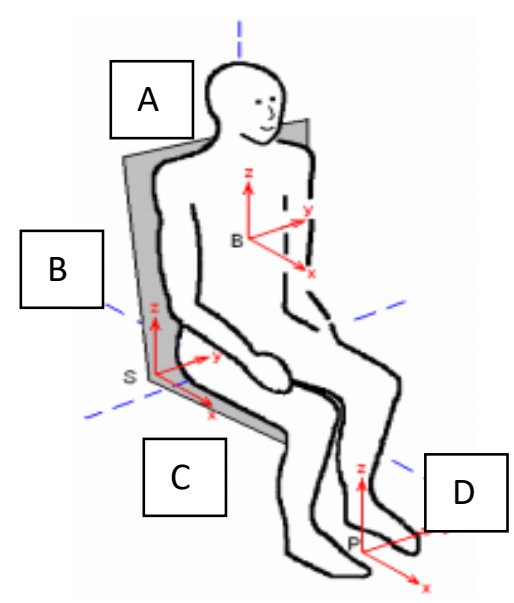

Figure 2. The illustration of transducer position during measurement with A:

microphone, B: SIT-PAD for the backrest, C: SIT-PAD for seat pan and; D: SIT-PAD for footrest.

\section{Evaluation of Noise and vibration}

The evaluation of noise and vibration was separately based on the existing standards and practice. For noise, the A-weighted sound pressure level parameter was calculated. The A-weighted sound pressure level is given by

$$
L_{\text {Aeq }}(d B A)=10 \log \left(\frac{1}{t_{2}-t_{1}} \int_{t_{1}}^{t_{2}} \frac{P_{A r m s}^{2}}{p_{r e f}^{2}} d t\right)
$$

Where pref is given by $20 \mu \mathrm{Pa}$. The A-weighting corresponds to the 40 -phon of equal loudness contour which passes through $40 \mathrm{~dB}$ at $1 \mathrm{kHz}$. This factor is considered based on the fact that human hearing is not equal in sensitivity at all frequency. The sound exposure level (SEL) describes the energy of noise with the respective duration. The Aweighted sound exposure level is given by Eq. (2).

$$
L_{A E}(d B A)=10 \log \left(\int_{t_{1}}^{t_{2}} \frac{P_{A r m s}^{2}}{p_{r e f}^{2}} d t\right)
$$

For vibration, the evaluation is based on ISO 2631-1 which involves the consideration of frequency weighted r.m.s. acceleration, which is given as Eq. (3).

$$
a_{w}\left[\frac{1}{T} \int_{0}^{T} a_{w}^{2}(t) d t\right]^{\frac{1}{2}}
$$


Where $a_{w}$ is the weighted r.m.s. acceleration of the vibration and $\mathrm{T}$ is the respective duration of the measurement, in seconds. In the case of crest factor being greater than 9, an additional vibration evaluation is required. The vibration dose value (VDV) was used as it is more sensitive to peaks than basic evaluation method. The fourth power vibration dose value is defined as Eq. (4)

$V D V=\left\{\int_{0}^{T}\left[a_{w}(t)\right]^{4} d t\right\}^{\frac{1}{4}}$

where $a_{w}(t)$ the frequency-weighted acceleration and $\mathrm{T}$ is the respective duration of the measurement. To quantify the severity of the WBV from the different axis, the total vibration can be determined based on ISO2631-1 as

$a_{v}=\sqrt{k_{x}^{2} a_{w x}^{2}+k_{y}^{2} a_{w y}^{2}+k_{z}^{2} a_{w z}^{2}}$

where $a_{w x}, a_{w y}, a_{w z}$ are weighted r.m.s acceleration with respect to $\mathrm{x}, \mathrm{y}$ and $\mathrm{z}$ axis respectively. The value for $\mathrm{k}$ in the scope of comfort vary according to location whether on seat pan, backrest or feet as indicated in Table 1.

Table 1. Suggested values of $\mathrm{k}$ according to ISO2631-1 in different axis and location.

\begin{tabular}{lllll}
\hline No & Location & $\mathrm{k}_{\mathrm{x}}$ & $\mathrm{k}_{\mathrm{y}}$ & $\mathrm{K}_{\mathrm{z}}$ \\
\hline 1 & Seat pan & 1 & 1 & 1 \\
2 & Back rest & 0.8 & 0.5 & 0.4 \\
3 & Feet & 0.25 & 0.25 & 0.4 \\
\hline
\end{tabular}

\section{MATHEMATICAL GOVERNING EQUATION FOR HUMAN RESPONSE TO NOISE AND VIBRATION}

\section{Psychophysical Relation of Subjective Magnitude of Stimulus with Objective Magnitude}

Stevens' Power Law is a law which relates the objective magnitude with human subjective response. This basic law has been a cornerstone for researchers in the field related to human response. In term of human response to combined noise and vibration, Steven's Power Law was used to quantify the discomfort of a human with noise and vibration. Steven's power law states that subjective response exponentially increases with the objective physical magnitude of a stimulus. It can be mathematically stated as Eq. (6).

$\psi=k \varphi^{n}$

where $\psi$ indicate the subjective magnitude, $\mathrm{k}$ is constant, $\varphi$ is the objective magnitude of stimulus and $\mathrm{n}$ is the stimulus-dependent exponent. The stimulus can be any kind of continuum which can affect human sensory such as sound loudness, vibration magnitude, temperature, the force of hand grip, the luminescence of light as well as the smell of coffee. In terms of noise and vibration, the subjective magnitude can be stated as 
$\psi_{n}=k_{n} \varphi_{n}^{\alpha_{n}}$

$\psi_{v}=k_{v} \varphi_{v}^{\alpha_{v}}$

where $\psi_{n}$ and $\psi_{v}$ represent the subjective magnitude for noise and vibration, $k_{n}$ and $k_{v}$ are constant for noise and vibration, $\varphi_{n}^{\alpha_{n}}$ and $\varphi_{n}^{\alpha_{n}}$ are the physical magnitude of noise and vibration respectively with their exponents. By using this relation, the subjective magnitude of noise and vibration can be written in log form as Eq. (9) and (10)

$$
\begin{aligned}
& \log \psi_{n}=\log k_{n}+\alpha_{n} \log \varphi_{n} \\
& \log \psi_{v}=\log k_{v}+\alpha_{v} \log \varphi_{v}
\end{aligned}
$$

By considering $a_{r m s} \propto \varphi_{v}$ and $L_{\text {Aeq }} \propto 20 \log \varphi_{n}$, Eq. (8) and (9) form a correlation of subjective magnitude with standardized objective magnitude.

$$
\begin{aligned}
& \log \psi_{n}=\log k_{n}+\frac{\alpha_{n}}{20} L_{\text {Aeq }} \\
& \log \psi_{v}=\log k_{v}+\alpha_{v} \log a_{r m s}
\end{aligned}
$$

\section{Values of Subjective Magnitude Exponent of $\alpha_{v}$ for Vibration and $\alpha_{n}$ for Noise}

\begin{tabular}{|c|c|c|c|c|}
\hline $\begin{array}{l}\text { Author, } \\
\text { year }\end{array}$ & Noise stimuli & $\begin{array}{l}\text { Vibration } \\
\text { stimuli }\end{array}$ & Method & Equation \\
\hline $\begin{array}{l}\text { Howarth \& } \\
\text { Griffin, } \\
1990 \\
{[24]}\end{array}$ & $\begin{array}{l}\text { 20-5000 Hz, } \\
54-79 \mathrm{dBA} \\
\text { SEL }\end{array}$ & $\begin{array}{l}0.07,0.1 \\
0.14,0.2 \\
0.28,0.4 \mathrm{~ms}^{-} \\
1.75 \mathrm{VDV}\end{array}$ & $\begin{array}{l}\text { Relative } \\
\text { magnitude } \\
\text { estimation }\end{array}$ & $\begin{array}{c}\log \psi_{s}=0.039 L_{A E}-0.663 \\
\log \psi_{v}=1.04 \log \left(a_{v d v}\right)+2.39\end{array}$ \\
\hline $\begin{array}{l}\text { (Howarth \& } \\
\text { Griffin, } \\
\text { 1991) } \\
{[25]}\end{array}$ & $\begin{array}{l}20-3000 \mathrm{~Hz} \\
52.5-77.5 \mathrm{dBA} \\
\text { SEL }\end{array}$ & $\begin{array}{c}10-60 \mathrm{~Hz} \\
0.056-0.4 \\
\mathrm{~ms}^{-1.75} \mathrm{VDV}\end{array}$ & $\begin{array}{l}\text { Relative } \\
\text { magnitude } \\
\text { estimation }\end{array}$ & $\begin{array}{c}\log \psi_{s}=0.036 L_{A E}-0.512 \\
\log \psi_{v}=1.186 \log \left(a_{v d v}\right)+2.57\end{array}$ \\
\hline $\begin{array}{l}\text { (Huang \& } \\
\text { Griffin, } \\
\text { 2012) } \\
{[26]}\end{array}$ & $\begin{array}{l}50-500 \mathrm{~Hz} \\
64-82 \mathrm{dBA}\end{array}$ & $\begin{array}{c}5-10 \mathrm{~Hz} \\
0.079-1.262 \\
\mathrm{~ms}^{-2} \mathrm{rms}\end{array}$ & $\begin{array}{l}\text { Absolute } \\
\text { magnitude } \\
\text { estimation }\end{array}$ & $\begin{aligned} \log \psi_{s} & =0.035 L_{A E}-0.923 \\
\log \psi_{v} & =0.947 \log \left(a_{v d v}\right)+1.852\end{aligned}$ \\
\hline
\end{tabular}

Previous researchers conducted psychophysics experiments to identify the values of $\alpha_{v}, \alpha_{n}$ of the equation by using different methods and frequency ranges of the stimuli.

Table 2. Previous model developed by researchers.

The value of the exponent $\alpha_{n}$ in the power function between loudness and SPL was agreed by many researchers to be 0.6 [27] which leads to the equation 
$\log \psi_{n}=0.033 L_{\text {Aeq }}+k$

Where $\mathrm{k}$ is a constant and $\mathrm{L}_{\mathrm{Aeq}}$ is the equivalent A-weighted sound pressure level. By taking the average value of $\mathrm{k}$ from the three equations from table 1, discomfort from noise can be predicted by

$\log \psi_{n}=0.033 L_{\text {Aeq }}-0.699$

Where $\psi_{n}$ is discomfort from noise and $L_{A e q}$ is A-weighted sound pressure level. The discomfort from vibration can be predicted by considering Huang and Griffin's equation[26] since the range of vibration dose values (VDV) of the experiment is related to the VDV values of the field measurement data in this study. The equation is given as:

$\log \psi_{v}=0.947 \log \left(a_{V D V}\right)+1.852$

Where $\psi_{v}$ is discomfort from vibration and $a_{V D V}$ is weighted vibration dose value acceleration.

\section{Root-sum-square Model of Discomfort of Combined Noise and Vibration.}

In vehicle cabins, noise and vibration affect humans simultaneously. Therefore, the evaluation of noise and vibration separately tend to underestimate the effect of noise and vibration towards human discomfort. A universal model of total discomfort of human can be written as

$\psi_{c}=\sqrt{\psi_{1}^{2}+\psi_{2}^{2}+\ldots \ldots+\psi_{n}^{2}}$

where $\psi_{1}, \psi_{2} \ldots \ldots \ldots, \psi_{1}$ represent discomfort from different factors when presented separately. By using this same model, total discomfort from noise and vibration for vehicle passenger in the vehicle cabin can be predicted. The total discomfort from combined noise and vibration can be predicted by the root sum square of the square of discomfort from noise and vibration separately

$\psi_{c}=\sqrt{\psi_{v}^{2}+\psi_{n}^{2}}$

where $\psi_{c}$ is the total discomfort from combined noise and vibration, $\psi_{v}$ is the discomfort from vibration and $\psi_{n}$ is the discomfort from noise. This equation can be expanded to include the effect of vibration in different position of the seat pan, backrest and feet.

$\psi_{c}=\sqrt{\psi_{v, \text { seat }}^{2}+\psi_{v, \text { back }}^{2}+\psi_{v, \text { feet }}^{2}+\psi_{n}^{2}}$

However, to simplify and simulating the dominant vibration exerted to a seated person, the equation can be reduced to only response to noise and vibration exposure to the seat pan in z-axis. The equation can be reduced to 
$\psi_{c}=\sqrt{\psi_{v, \text { seat }-z}^{2}+\psi_{n}^{2}}$

where $\psi_{v, \text { seat }-z}$ is the discomfort level from the seat pan in the $\mathrm{z}$-axis (vertical vibration) and $\psi_{n}$ is the discomfort from noise. This root-sum-square model is the basis of quantifying noise and vibration as a combined modality.

\section{Simulating Discomfort from Combined Noise and Vibration}

By considering Eq. (12) and (13), discomfort in a vehicle from noise and WBV on seat pan can be predicted by

$\psi_{c}=\sqrt{10^{1.894 \log \left(a_{v d v}\right)+3.704}+10^{0.066 L_{\text {Aeq }}-1.382}}$

where $L_{\text {Aeq }}$ is the A-weighted noise pressure level and $a_{v d v}$ is vibration dose value acceleration level.

The complexity of discomfort study can be increased by considering other parameters which affecting discomfort in vehicle cabin such as temperature, posture, sight, driving condition, aesthetic of interior, roll motion of vehicle and hand-arm vibration. The ideal model needs to consider all these factors to accurately predict actual human discomfort in the vehicle. However, the study of a combination of some of the factors lead to a good understanding on how to provide the best prediction for discomfort.

\section{RESULTS AND DISCUSSION}

\section{Whole-body Vibration and Noise Level in Vehicle for Different Operating Speed}

The result generally suggested that the whole-body vibration on seat pan and feet showed clear dominant of Z-Axis vertical vibration exposure for both vehicle $\mathrm{A}$ and $\mathrm{B}$ whereby backrest is dominant in the $\mathrm{x}$-axis as indicated in Figure 3 and 4 . At the seat pan and feet position, whole-body vibration of $\mathrm{x}$ and $\mathrm{y}$-axis shows complex variation with vehicle speed. These findings indicated that vehicle passenger exposed to higher exposure to WBV as the speed of vehicle increases. This is in agreement with a previous study of WBV in a vehicle at different speeds $[11,12]$. As referring to Figure 3(a) and 3(b), it can be observed that high exposure in $\mathrm{z}$-axis vertical vibration on seat pan for both vehicles followed by $\mathrm{x}$-axis and $\mathrm{y}$-axis. For backrest, the dominant exposure is in the $\mathrm{x}$-axis which relates to the fore-and-aft motion. The fore-and-aft vibration was found to be higher at higher vehicle speed. This contributes to elaborate the previous research on fore-and-aft vibration exposure research related to vibration transmissibility [28] where the previous research findings suggested that the highest vibration transmission during fore-and-aft vibration is at the centre of the vehicle seat. The result from the research and these current findings could lead to the conclusion that at higher vehicle speed, vibration exposure at vehicle backrest are higher and highly concentrated at the centre of the seat backrest. In terms of noise exposure, it can be observed from Figure 3(d) and 4(d) that the noise level increases as the vehicle speed increase. 


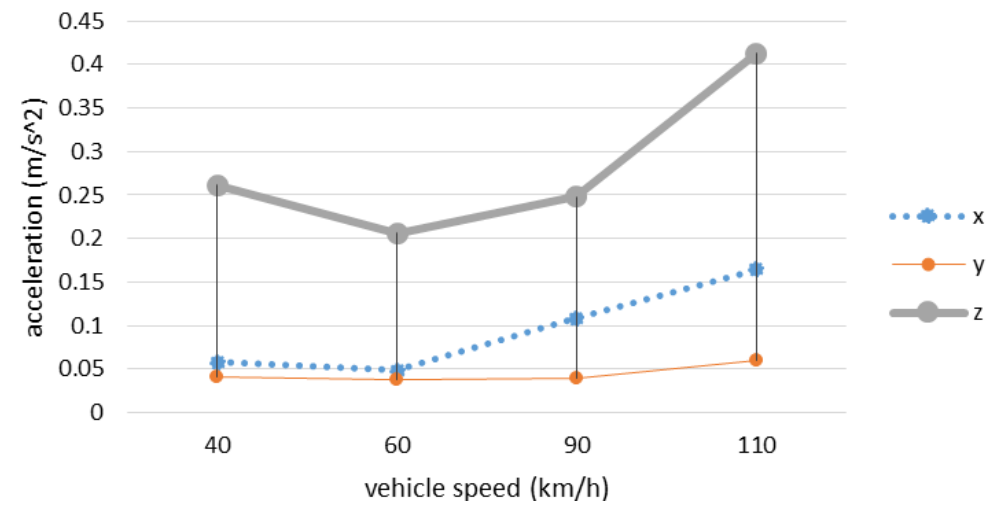

(a)

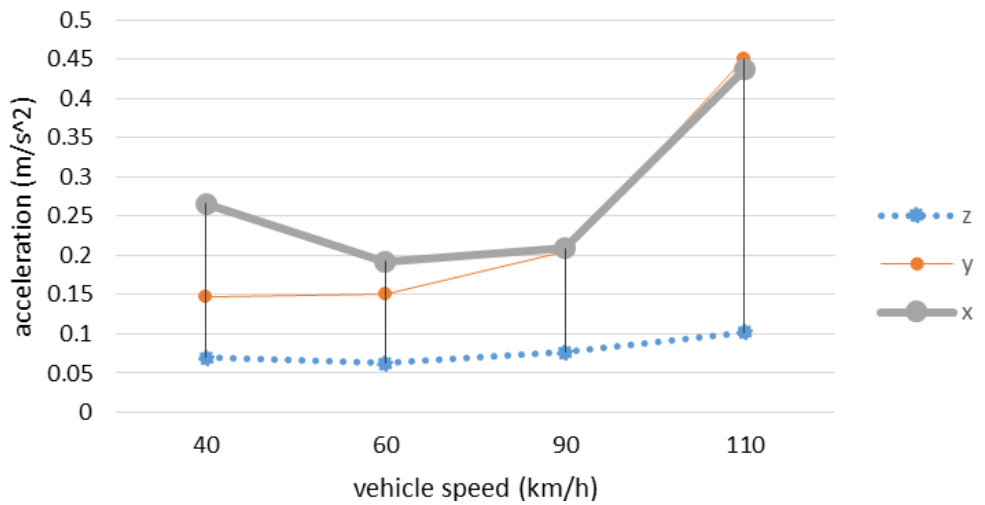

(b)

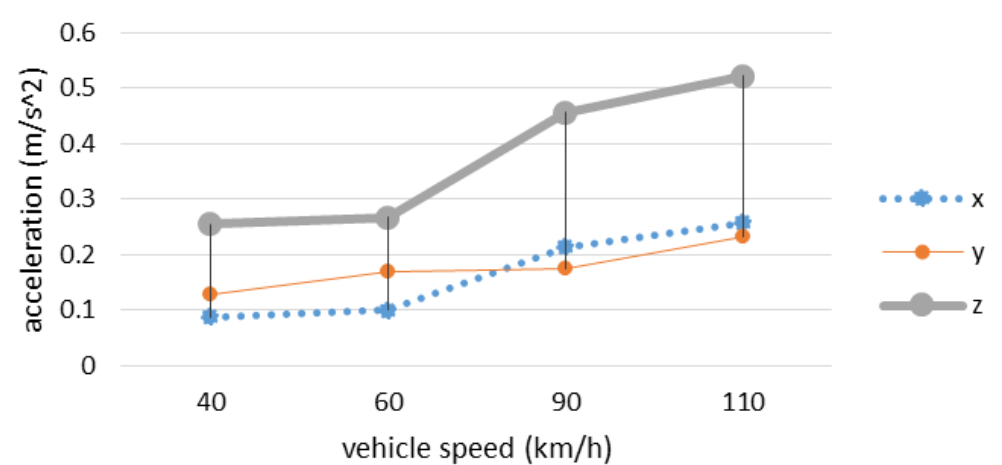

(c)

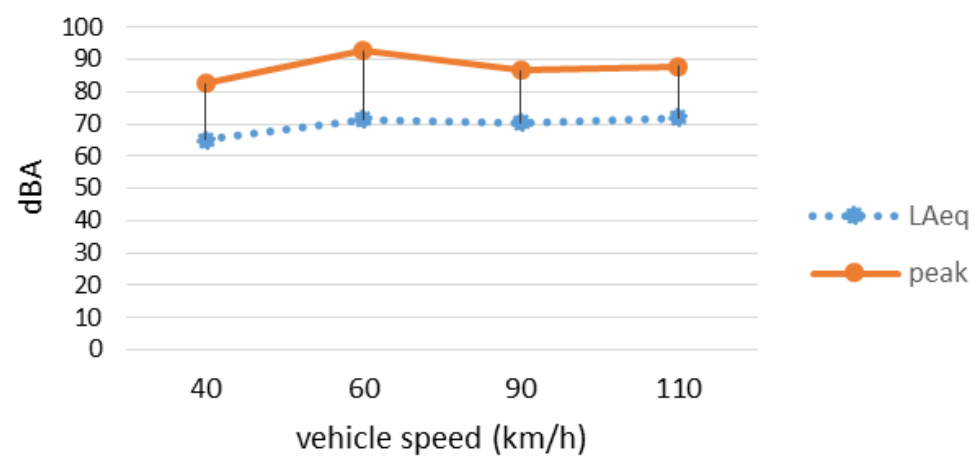

(d)

Figure 3. Whole body exposure in x,y and z-axis for (a) seat pan, (b) backrest, (c) feet and; (d) A-weighted sound pressure level at the ear position of vehicle A (Perodua Alza). 
The findings in Figure 5 indicate exposure to vibration in a vehicle is higher at the feet compared to backrest and seat pan with respect to the z-axis. Vibration on feet can be studied separately as local vibration case. The exposure of vibration on feet could lead to discomfort, ache or pain depends on the frequency content and magnitude of the vibration [29]. It also can be observed that the same dominant vibration on feet for both vehicle A and vehicle B but with different behaviour as in Figure 5(a) and 5(b). Vehicle A showed a steady increment of vibration with increasing speed but vehicle B recorded decrement of vibration exposure on feet at $90 \mathrm{~km} / \mathrm{h}$ but increase tremendously at 110 $\mathrm{km} / \mathrm{h}$. For other axes, Vehicle A showed the backrest was the second dominant vibration in the z-axis and the seat pan had the least magnitude of vibration. This result contradicts with vehicle $B$ as the second dominant vibration was found to be at the seat pan. So many factors could lead to these findings. For example, road surface, seat cushion used by the vehicle as well as passenger weight.

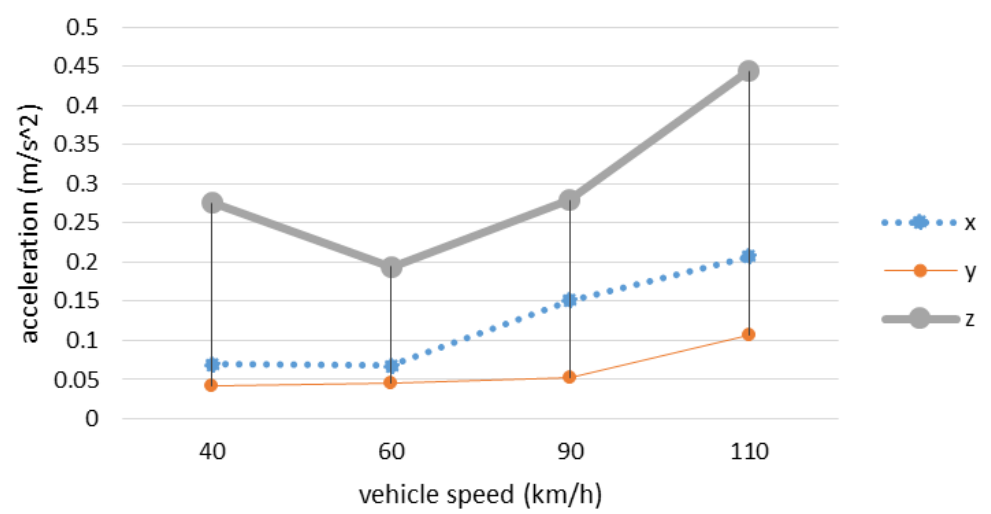

(a)

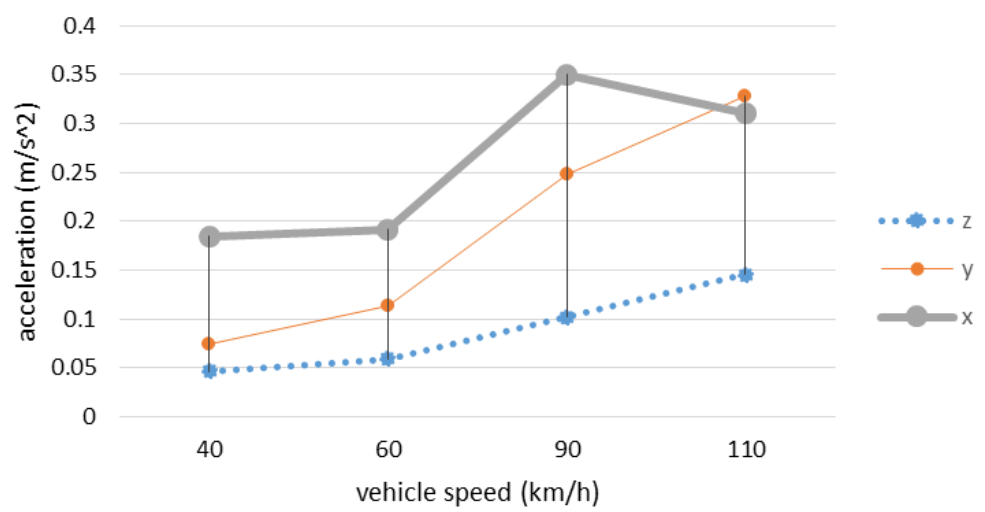

(b)

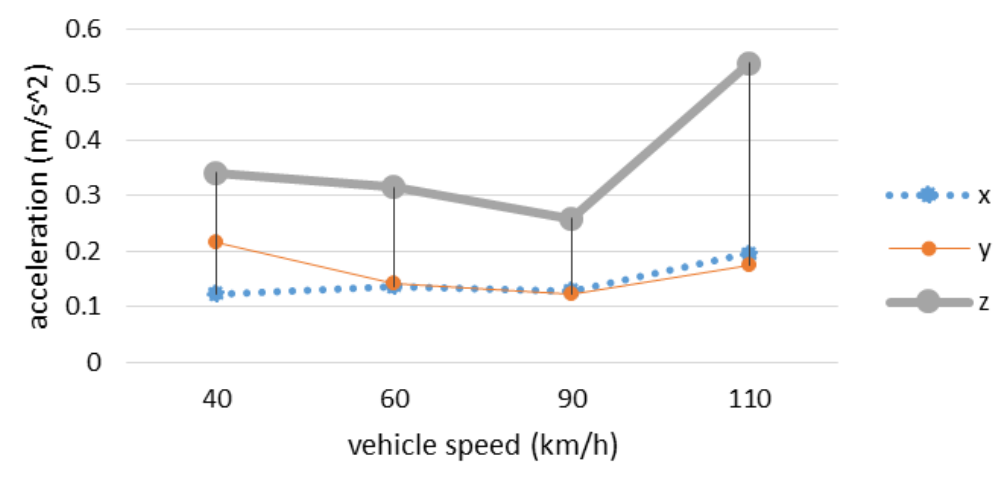

(c) 


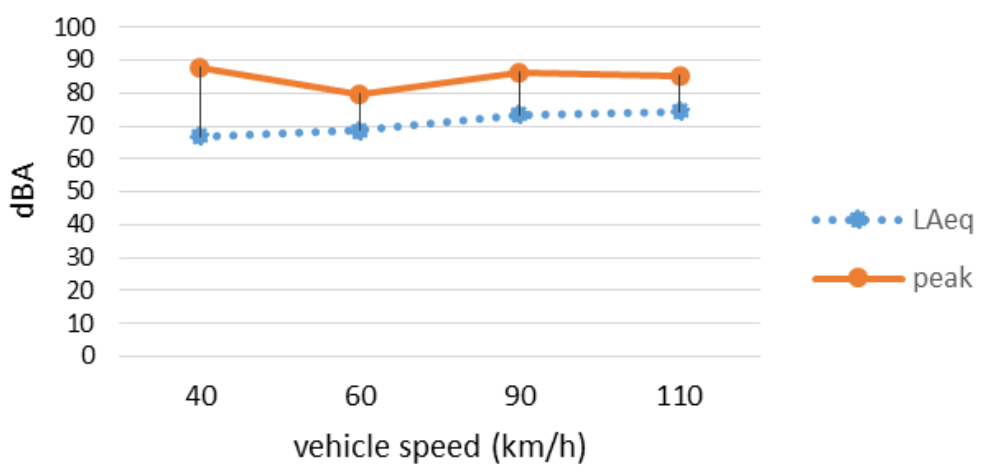

(d)

Figure 4. Whole body exposure in $\mathrm{x}, \mathrm{y}$ and $\mathrm{z}$-axis for (a) seat pan, (b) backrest, (c) feet and (d) A-weighted sound pressure level at the ear position of vehicle B (Perodua

Myvi).

To identify the relative exposure of human to noise and vibration between two vehicles, Figure 6(a) and 6(b) showed the objective quantification of noise and vibration level as a separate modality in vehicle between two cars. Figure 6(a) indicates that at low speed, vehicle $\mathrm{B}$ has a lower vibration dose values (VDV) compared to vehicle A. However, at the high speed of $110 \mathrm{~km} / \mathrm{h}$, vehicle B shows higher VDV values. For sound level, vehicle B provides a comparatively higher sound level exposure to vehicle passenger at higher speeds than vehicle A. For total vibration values, vehicle $\mathrm{A}$ is found to have higher values at most of the operating speeda as indicated in Figure 7 . The result for the two vehicles is not intended to compare the quality between them, as the vehicles does not share the same manufacturing date. The main idea is to observe how objective quantification of noise and vibration can be done as separate modalities and compared between two vehicles. However, it could be a baseline for future researches of WBV in vehicles. The quantification could give relative vibration and noise severity between vehicles, but to be discussed separately in terms of vibration and noise.

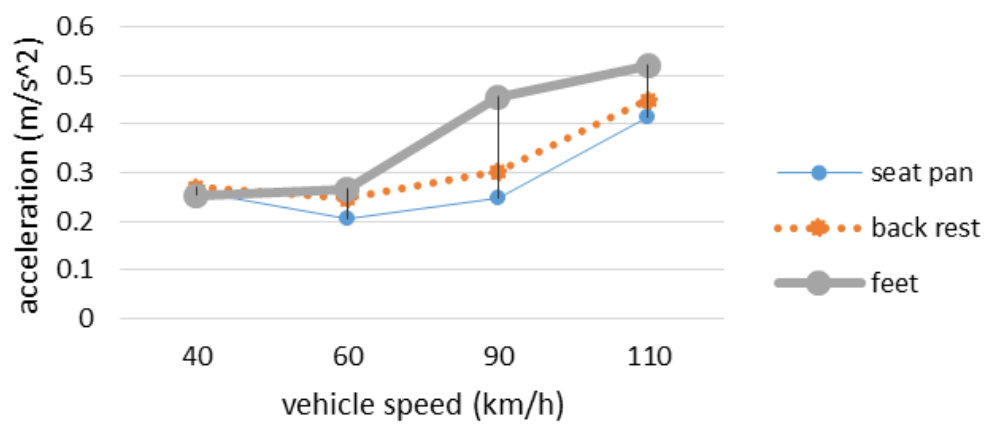

(a) 


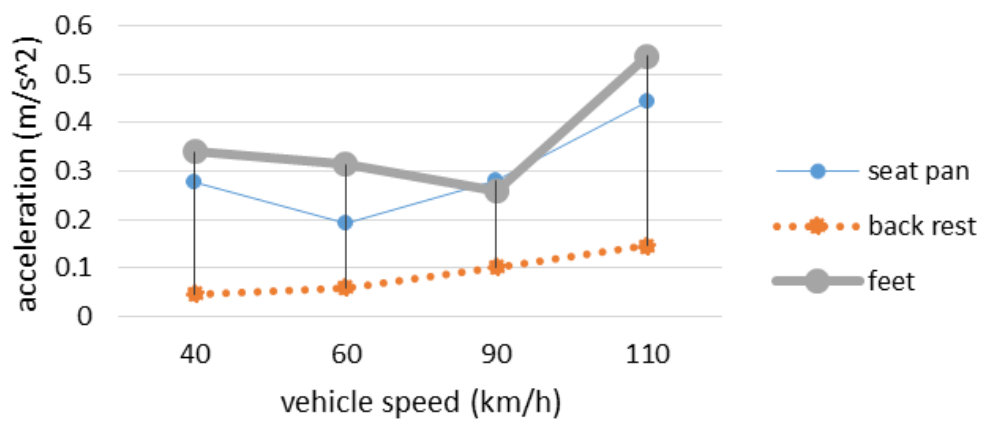

(b)

Figure 5. Comparison of whole-body exposure in the z-axis for on the seat pan, backrest and footrest for vehicle (a) A-Perodua Alza and; (b) B-Perodua Myvi.

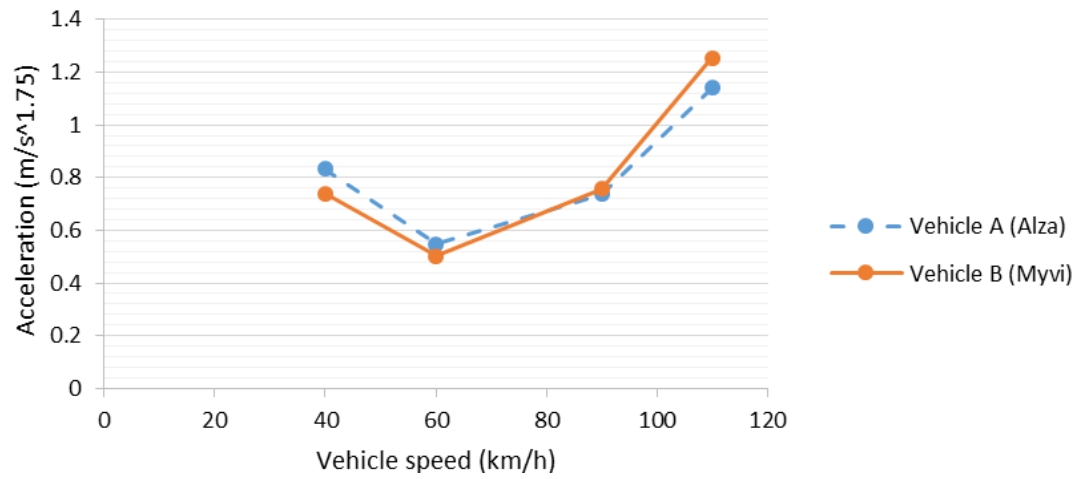

(a)

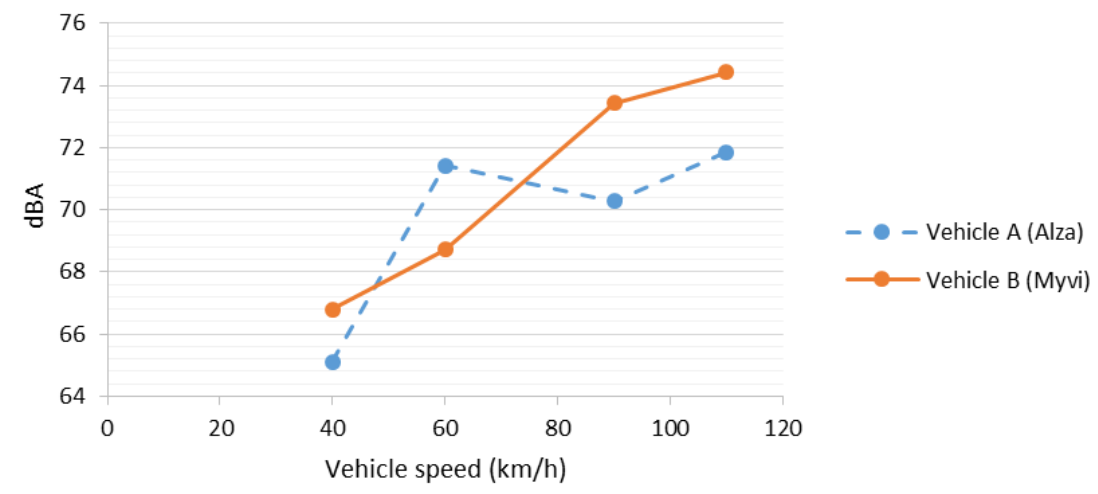

(b)

Figure 6. Evaluation of WBV and noise exposure separately between two vehicles (a) vibration dose values on seat pan z-axis for two different vehicles and (b) A-weighted sound pressure level comparison between two vehicles. 


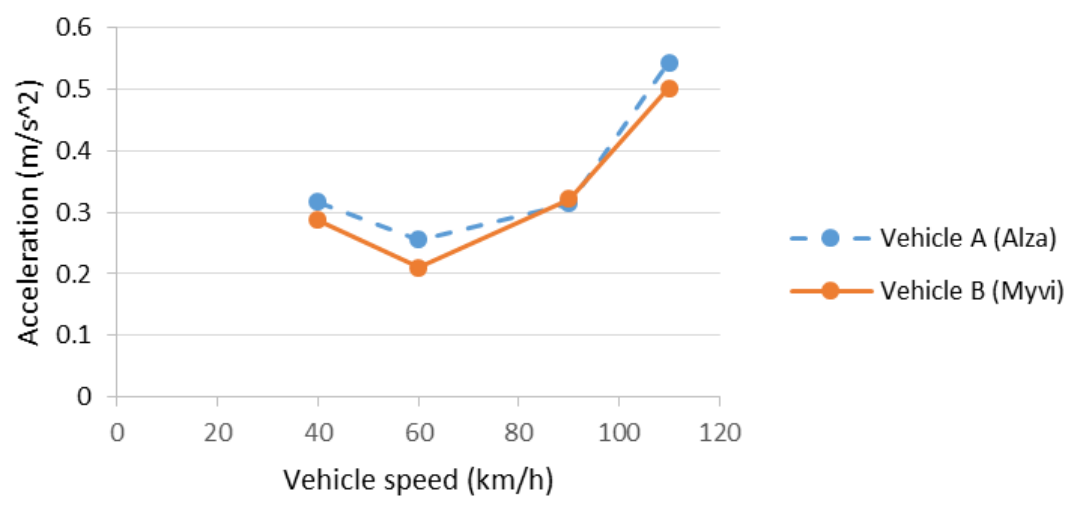

Figure 7. Total vibration values of WBV on seat pan calculated based on ISO2631-1 for vehicle $A$ and $B$.

\section{Discomfort in Vehicle Cabin from Combined Noise and Vibration}

The discomfort from noise and vibration can be quantified as combined modalities. The effect of combined noise and vibration can be predicted using the discomfort model derived from psychophysics experimental work. The equation can relatively indicate the level of discomfort of a passenger in a vehicle and subsequently be developed into methods in indicating relative discomfort level in the vehicle. Figure 8(a) shows a variation of discomfort from the combined noise and vibration in a vehicle under different operating speeds and between two different types of vehicles by applying the root-sumsquare-model equation (20). The Relative Discomfort Indicator (RDI) is now introduced as a complementary variable to quantify the differences between the level of discomfort. RDI can be calculated by

Relative Discomfort Indicator, $R D I_{A-B}=\frac{\psi_{A}-\psi_{B}}{\psi_{A}}$

Where $R D I_{A-B}$ is the relative discomfort indicator of vehicle $\mathrm{A}$ to vehicle $\mathrm{B}, \psi_{A}$ is the total discomfort for vehicle $\mathrm{A}$ and $\psi_{B}$ is the total discomfort for vehicle B. Positive RDI means vehicle $\mathrm{A}$ is having a higher discomfort level compared to vehicle B. Negative RDI indicates that vehicle $\mathrm{A}$ has less discomfort level compared to vehicle B.

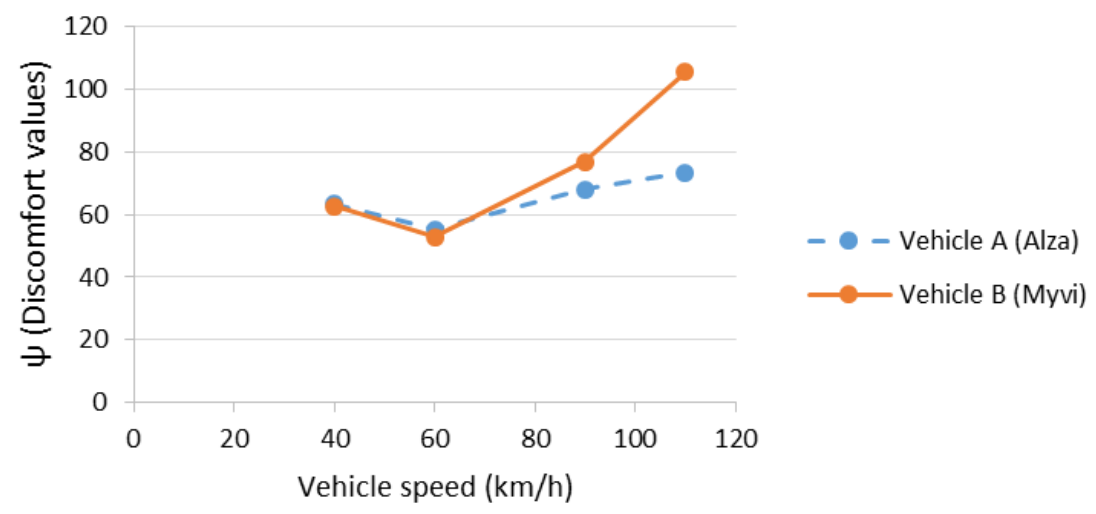

(a) 


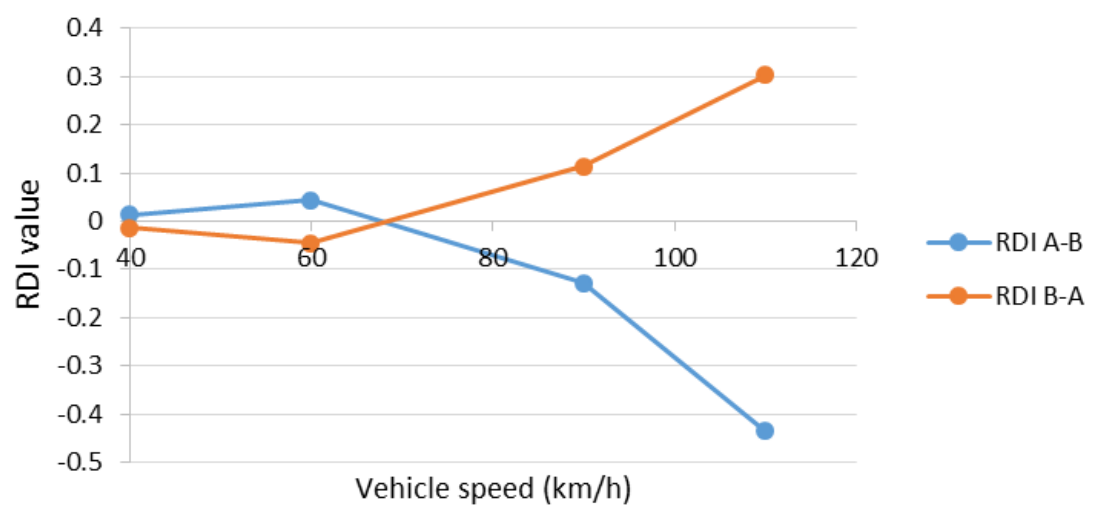

(b)

Figure 8. Discomfort comparison for combined seat pan z-axis vibration and noise, (a) discomfort values and (b) Relative Discomfort Indicator (RDI) for discomfort evaluation

For example, $\mathrm{RDI}_{\mathrm{A}-\mathrm{B}}=0.13$ means at that speed, the passenger in vehicle $\mathrm{A}$ is having $13 \%$ more discomfort compared to the passenger in vehicle $\mathrm{B}$. For a negative value, it shows the other way around. This method is expected to be useful to evaluate vehicle noise, vibration and Harshness (NVH) quality by making a comparison between vehicles that have been benchmarked. Figure 8 showed that discomfort in vehicle $\mathrm{A}$ is dominant at low speed compared to vehicle B. However, at higher speeds, vehicle B produces more discomfort to its passenger. The RDI can be applied as a method to evaluate discomfort level in vibro-acoustic environment such as in the vehicle cabin, comparing it to another benchmarked vehicle. The advantage of this method is the simpler indication with a single variable consideration compared to the conventional method where vibration and noise exposure are quantified separately, and severity depends on general limitation values stated by standards or references of vibration and noise level.

\section{CONCLUSION}

In this research, the noise and vibration in two different vehicles were measured and evaluated using international standard ISO 2631-1. The findings from previous research work were used to formulate and simulate the discomfort of noise and vibration as combined modalities. The key findings of the research can be summarized as below:

i. A passenger in a vehicle have the highest vibration exposure in the $\mathrm{z}$-axis (vertical vibration) on the seat pan and feet, but in the $x$-direction (fore-and-aft), the vibration exposure is on the seat backrest.

ii. Noise and vibration exposure to a passenger in a vehicle increases as the vehicle's operating speed increases.

iii. The discomfort from noise and vibration can be evaluated as combined modalities. The root-sum-square model was applied to predict discomfort from combined noise and vibration. The Relative Discomfort Indicator (RDI) was introduced as a complementary variable to evaluate the comfort level of a passenger in a vehicle by comparison. The method is expected to be beneficial for quality improvement and benchmarking process in automotive NVH enhancements. 


\section{ACKNOWLEDGEMENT}

The authors would like to be thank Universiti Putra Malaysia (UPM) and Taylor's University for field measurement work and research resources support. The research work was partially supported by research grant TRGS/ERFS/1/2017/SOE/024

\section{REFERENCES}

[1] Dhingra H, Tewari V, Singh S. Discomfort, pressure distribution and safety in operator's seat - A critical review. Agricultural Engineering International 2003; V: $1-16$.

[2] Azlis-sani J, Firdaus M, Bin Zaid, et al. Evaluation of whole body vibration and back pain problem among light rapid transit (LRT) drivers. Applied Mechanics and Materials 2015; 773-774: 845-849.

[3] Griffin MJ. Discomfort from feeling vehicle vibration. User Modeling and UserAdapted Interaction 2007; 45: 679-698.

[4] ISO. ISO 2631-1 Mechanical vibration and shock - Evaluation of human exposure to whole-body vibration - Part 1: General requirements. 1997; 31.

[5] Nahvi H, Nor M, Fouladi M, et al. Evaluating automobile road vibrations using BS 6841 and ISO 2631 comfort criteria. In: 1st Regional Conference on Vehicle Engineering \& Technology. 2006, pp. 1-8.

[6] Thamsuwan O, Blood RP, Ching RP, et al. Whole body vibration exposures in bus drivers: A comparison between a high-floor coach and a low-floor city bus. International Journal of Industrial Ergonomics 2013; 43: 9-17.

[7] Paddan G, Griffin M. Evaluation of whole-body vibration in vehicles. Journal of Sound and Vibration 2002; 253: 195-213.

[8] Altinsoy ME. Identification of quality attributes of automotive idle sounds and whole-body vibrations. International Journal of Vehicle Noise and Vibration 2013; 9: 4.

[9] Kumar V, Saran V, Guruguntla V. Study of vibration dose value and discomfort due to whole body vibration exposure for a two wheeler drive. In: Proceedings of the 1st International and 16th National Conference on Machines and Mechanisms (iNaCoMM2013). 2013, pp. 947-952.

[10] Purcell E. Whole-body vibration of heavy mobile equipment operators at an opencast mine. Stellenbosch University, 2017.

[11] Nahvi H, Fouladi MH, Mohd Nor MJ. Evaluation of whole-body vibration and ride comfort in a passenger car. International Journal of Acoustics and Vibrations 2009; 14: $143-149$.

[12] Duarte MLM, de Melo GC. Influence of pavement type and speed on whole body vibration (WBV) levels measured on passenger vehicles. Journal of the Brazilian Society of Mechanical Sciences and Engineering 2018; 40: 150.

[13] Radic N, Novak C, Ule H. Experimental evaluation of vehicle cabin noise using subjective and objective psychoacoustic analysis techniques. Journal of the Canadian Acoustical Association 2011; 39: 27-36.

[14] Aladdin MF, Jalil NAA. Psychoacoustic bias in vehicle interior noise - preliminary study. Procedia Engineering 2017; 170: 217-225.

[15] van Waterschoot T, Jensen SH, Bech S, et al. Perceptual aspects of reproduced sound in car cabin acoustics. The Journal of the Acoustical Society of America 2017; 141: 1459-1469. 
[16] Al-Dhahebi AM, Junoh AK, Mohamed Z, et al. A computational approach for optimizing vehicles' interior noise and vibration. International Journal of Automotive and Mechanical Engineering 2017; 14: 4690-4703.

[17] Li D, Huang Y. The discomfort model of the micro commercial vehicles interior noise based on the sound quality analyses. Applied Acoustics 2018; 132: 223-231.

[18] Huang Y, Griffin MJ. The discomfort produced by noise and whole-body vertical vibration presented separately and in combination. Ergonomics 2014; 57: 17241738.

[19] Daruis DDI, Nor MJM, Fouladi MH, et al. Driver's perception on the influence of interior sound to vertical whole-body vibration. In: 16th International Congress on Sound and Vibration 2009, ICSV 2009. 2009, pp. 5-9.

[20] Parizet E, Amari M, Roussarie V. Contribution of noise and vertical vibration to comfort in a driving car. EuroRegio 2010 2010; 1.

[21] Maigrot P, Marquis-Favre C, Parizet E. Annoyance due to railway noise and vibrations: A comparison of two methods of collecting annoyance scores. The Journal of the Acoustical Society of America 2017; 141: 3693-3694.

[22] Huang Y, Li D. Subjective discomfort model of the micro commercial vehicle vibration over different road conditions. Applied Acoustics 2019; 145: 385-392.

[23] Mansfield NJ. Human Response to vibration. CRC Press, 2004.

[24] Howarth HVC, Griffin MJ. The relative importance of noise and vibration from railways. Applied Ergonomics 1990; 21: 129-134.

[25] Griffin MJ, Howarth H. The annoyance caused by simultaneous noise and vibration from railways. Journal of the Acoustical Society of America 1991; 89: 2317-2323.

[26] Huang Y, Griffin MJ. The effects of sound level and vibration magnitude on the relative discomfort of noise and vibration. The Journal of the Acoustical Society of America 2012; 131: 4558-4569.

[27] Huang Y. Human response to combined noise and vibration. University of Southampton, 2012.

[28] Abdul Jalil NA, Griffin MJ. Fore-and-aft transmissibility of backrests: Variation with height above the seat surface and non-linearity. Journal of Sound and Vibration 2007; 299: 109-122.

[29] Eger T, Thompson A, Leduc M, et al. Vibration induced white-feet: overview and field study of vibration exposure and reported symptoms in workers. Work 2014; 47: $101-10$. 